\title{
SODIUM AND POTASSIUM ELECTROLYTES AND "BASAL" SKIN POTENTIAL LEVELS IN MALE AND FEMALE SUBJECTS
}

\author{
Margaret J. Christie and Peter H. Venables ${ }^{1}$ \\ Department of Psychology, Birkbeck College, University of London
}

\begin{abstract}
Summary When palmar skin potential level (SPL) is recorded during periods of minimal arousal sweating, and a concentration of potassium chloride within physiological limits is used for the external electrolyte, the value of the "basal" SPL (BSPL) recorded can be expressed as a function of the external/epidermal potassium concentration gradient.

The present study reports comparison of BSPL values obtained with the use of physiologically comparable concentrations of sodium and potassium chlorides. The results suggest the possibility that the BSPL methodology may provide a means of monitoring electrolyte shifts in the human subject.

In addition, sex differences in BSPL values were demonstrated.
\end{abstract}

Palmar skin potential level (SPL) is one of the electrodermal measures that can be recorded from human subjects and used to assess their psychophysiological state (VENABLES and MARTIN, 1967a); human SPL is usually negative at a palmar surface electrode with reference to an "inactive" electrode site on an ipsilateral, abraded, forearm surface. The electrodes used may be of a silver/silver chloride $(\mathrm{Ag} / \mathrm{AgCl})$ chamber type, with sodium or potassium chloride $(\mathrm{NaCl}, \mathrm{KCl})$ as the external electrolyte at the two electrode/epidermal interfaces (VENABLES and SAYER, 1963). The negativity of SPL decreases with decreasing arousal (LEIDERMAN and SHAPIRO, 1964; Christie, 1970), a condition in which palmar sweating is reduced (MARTIN and VeNABLES, 1966) if ambient temperatures are moderate (NeUMANN, 1968, p. 110). The absolute value of SPL has, however, been reported to be lowered when the concentration of the external electrolyte is reduced (VENABLes and SAYer, 1963; Rothman, 1954; EDELBERG, 1963).

Examination of the physiological mechanisms underlying electrodermal phenomena has suggested that sudorific factors may be significantly implicated in the generation of SPL (MARTIN and VenAbles, 1966): VenAbles and MARTIN

Received for publication July 23, 1971

1 This work was supported by the Social Science Research Council. 
(1967b) used an iontophoretic technique with hyoscyamine to block palmar eccrine sweat glands, measuring SPL before and after eccrine sweating had been eliminated (the glands being sympathetically innervated, with a cholinergic synapse at the nerve/target-organ junction). After such treatment SPL was found to be reduced by only $25 \%$ of its pretreatment value, leaving a major portion of the measured SPL to be accounted for in terms of nonsudorific contributions.

One nonsudorific factor that merits consideration is the ionic concentration of the external electrolyte: although there is reported lowering of measured SPL by reduction in the external electrolyte concentration, findings have at times been equivocal. EDELBERG (1963), when using $\mathrm{NaCl}$, found some subjects in whom the concentration effect was not demonstrable, and NiImI et al. (1968) were unable to demonstrate any significant changes in recorded SPL when they varied the concentration of their external $\mathrm{NaCl}$. They offered the suggestion that previously reported concentration effects had been the result of earlier workers having employed dissimilar concentrations of electrolyte at the forearm and palmar electrodes; Nirmi et al. did, however, conclude that an "element of confusion" remained in the area of SPL-electrolyte relations.

Consideration of possible sources of such "confusion" may, at this point, usefully be subsumed under two headings:

1. The nature of the SPL recorded in any concentration-effect studies

2. The qualitative and quantitative nature of the external electrolyte

1. The nature of the SPL recorded. A series of studies (CHRISTIE, 1970) centering around the recording, with external $\mathrm{KCl}$, of SPL from wholly relaxed, unstimulated human subjects in temperate conditions has suggested that when subjects are in this "basal" state palmar eccrine sweat glands are minimally active, and the nonsudorific generation of SPL provides a major portion of its measured value (Christie and Venables, 1971a). The measured SPL at a "basal" point (BSPL) was shown to have a significant inverse correlation $(r=-0.7, P<0.001)$ with the amplitude of the electrocardiogram (ECG) T-wave. As this amplitude increases when $\mathrm{KCl}$ is ingested (MASHIMA et al., 1965) and is significantly correlated $(r=0.68, P<0.001)$ with plasma potassium concentration $\left(\left[\mathrm{K}^{+}\right]\right)$ (PAPADIMITRIOU et al., 1970), its significant inverse correlation with BSPL is taken as evidence for the importance of a nonsudorific factor related to extracellular fluid (ECF) $\left[\mathrm{K}^{+}\right]$in the generation of BSPL.

2. The nature of the external electrolyte. Our series of studies was undertaken with $0.5 \% \mathrm{KCl}$ as the external electrolyte. It has, in the past, been tacitly assumed that $\mathrm{NaCl}$ can be substituted for $\mathrm{KCl}$ as an external electrolyte; this may be so if SPL is recorded in other than the "basal" state, and if the electrodeelectrolyte system has, in consequence, what is primarily a transducer function in the recording of potentials that originate from sweat glands. In "basal" conditions, however, we would argue that our electrode- $\mathrm{KCl}$ system is implicated 
in the generation of BSPL and would argue further that ECF $\left[\mathrm{K}^{+}\right]$is also a relevant factor.

Given, then, the fact that low BSPL values are associated with high ECF $\left[\mathrm{K}^{+}\right]$ (Christie and Venables, 1971c), and with low external [ $\left.\mathrm{K}^{+}\right]$(Venables and SAYER, 1963), this suggests the Nernst equation as a possible model to relate the potentials generated by nonsudorific factors to the external/internal concentration gradients:

$$
\mathrm{BSPL}=\underset{\left(61 \text { at } 37^{\circ} \mathrm{C}\right)}{\operatorname{constant}} \times \log _{10} \frac{\left[\mathrm{K}^{+}\right]_{\text {external }}}{\left[\mathrm{K}^{+}\right]_{\text {internal }}}
$$

The Nernst model was used in a study where values of $\left[\mathrm{K}^{+}\right]$external were varied systematically in a range below $67 \mathrm{mEq} / 1 \mathrm{~K}^{+}(0.5 \% \mathrm{KCl})$, and where values of recorded BSPL suggested that, within physiological levels of $\left[\mathrm{K}^{+}\right]$external, the model appeared to have relevance.

Thus, in contrast to the report of NiIMI et al. (1968), a reduction in BSPL was associated with a reduction in external electrolyte concentration, but two aspects of the statement require emphasis: first, the reduction in recorded potential level was demonstrated for "basal" SPL, and the extent to which NIIMI et al. were recording "basal" or nonbasal (i.e., sudorific) data is not known. Second, the external electrolyte used by us was $\mathrm{KCl}$, not $\mathrm{NaCl}$, as employed by NIIMI et al.; all our previous work with BSPL has been undertaken with the $0.5 \% \mathrm{KCl}$ recommended by Venables and SAYER (1963) as being optimal for SPL measurement. Furthermore, as there were indications that external electrolyte concentrations should match physiological values, external values were varied only below $0.5 \%$ $\mathrm{KCl}$.

The consequence of previous BSPL investigations having been undertaken with $0.5 \% \mathrm{KCl}$ is that we are not as yet able to assess the extent to which $\mathrm{NaCl}$ is a substitute for $\mathrm{KCl}$ in BSPL recording, or to assess the extent to which the results of NiImI et al. are attributable to the qualitative or quantitative differences in their external electrolyte. In order to initiate comparison of $\mathrm{NaCl}$ and $\mathrm{KCl}$ for BSPL recording, the study reported herein was undertaken; its primary aim was a comparison of BSPL values obtained with the two external electrolytes when these were of physiologically comparable concentrations. Thus it was argued that for their concentrations to be comparable it was important that:

$\left[\mathrm{Na}^{+}\right]_{\text {external }} /\left[\mathrm{Na}^{+}\right]_{\text {internal }}$ was similar to $\left[\mathrm{K}^{+}\right]_{\text {external }} /\left[\mathrm{K}^{+}\right]_{\text {internal }}$ rather than having the absolute values of $\left[\mathrm{K}^{+}\right]_{\text {external }}$ and $\left[\mathrm{Na}^{+}\right]_{\text {external }}$ be similar. A subsidiary aim of the study was the investigation of sex differences in recorded BSPL, all previous studies having been undertaken with male subjects only.

\section{METHOD}

a) The selection of external electrolyte concentrations

1. $\left[\mathrm{K}^{+}\right]_{\text {external }}$. Although $67 \mathrm{mEq} / 1 \mathrm{~K}^{+}(0.5 \% \mathrm{KCl})$ was originally selected 
Table 1. Palmar surface film: normative data from three previous studies.

\begin{tabular}{clcccc}
\hline $\begin{array}{c}\text { Study } \\
\text { No. }\end{array}$ & $\begin{array}{c}\text { Time of } \\
\text { day }\end{array}$ & $\begin{array}{c}\text { Climatic } \\
\text { conditions }\end{array}$ & $\begin{array}{c}\text { Mean palmar } \\
\text { surface output } \\
(\mathrm{mg} / \mathrm{hr})\end{array}$ & $\begin{array}{c}\text { Mean palmar } \\
{\left[\mathrm{K}^{+}\right]} \\
(\mathrm{mEq} / 1)\end{array}$ & $\begin{array}{c}\text { Mean palmar } \\
\mathrm{Na} / \mathrm{K}\end{array}$ \\
\hline $1(n=14)$ & Noon & $\begin{array}{c}\text { Summer } \\
(\text { hot })\end{array}$ & 42.3 & 16.20 & 2.43 \\
$2(n=20)$ & Evening & $\begin{array}{c}\text { Summer } \\
(\text { hot })\end{array}$ & 43.5 & 16.70 & 2.42 \\
$3(n=20)$ & Noon & $\begin{array}{c}\text { Summer } \\
(\text { cool) }\end{array}$ & 53.9 & 18.97 & 1.96 \\
$\begin{array}{c}\text { Winter } \\
(\text { cool) } \\
\text { Grand } \\
\text { mean }\end{array}$ & 50.35 & 20.80 & 1.76 \\
\hline
\end{tabular}

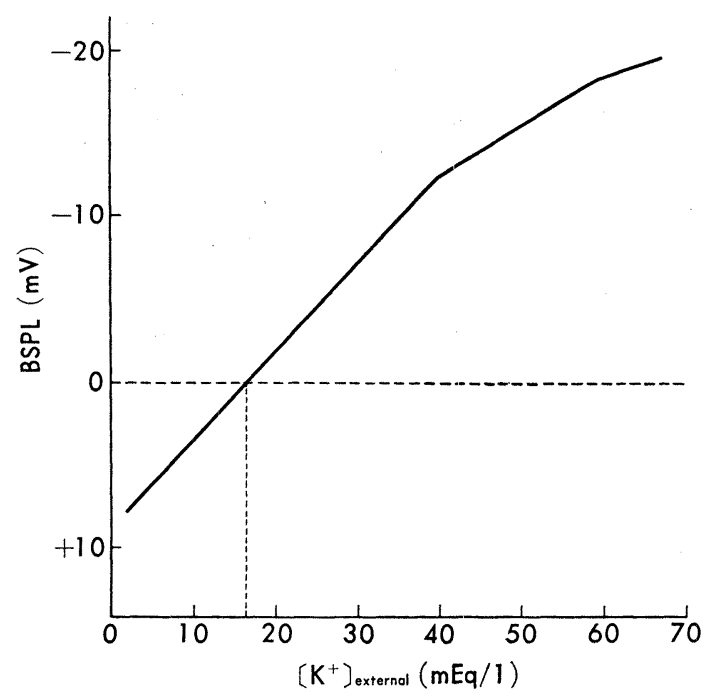

Fig. 1. Changes in measured BSPL associated with changes in $\left[\mathrm{K}^{+}\right]_{\text {external. }}$.

by Venables and SAYer (1963) as being an optimal concentration of external electrolyte for recording SPL (that is, for recording levels above the "basal" state), Christie and Venables (1971b) have suggested that $\left[\mathrm{K}^{+}\right]_{\text {internal }}$ concentrations are below this value, and that a $\left[\mathrm{K}^{+}\right]_{\text {external }}$ slightly less than $67 \mathrm{mEq} / 1$ would be preferable for recording BSPL. Selection of an appropriate concentration was, therefore, made with reference to Table 1 and Fig. 1.

Table 1 presents normative data from three studies concerned primarily with investigation of the $\left[\mathrm{K}^{+}\right]$of palmar surface film. This fluid was collected from male subjects at the times and under the climatic conditions detailed in the table. Methods of collection and analysis are detailed elsewhere (VenABles and CHRISTIE, in preparation); briefly, the film is collected during a 60 -min period in temperate 
surroundings (e.g., in an experimental environment maintained at $23^{\circ} \mathrm{C}$ ), from subjects in states of low arousal. Given such conditions it becomes possible that palmar surface film can reflect the composition of its precursory intercellular fluid in the clefts of the horny layer. The $\left[\mathrm{K}^{+}\right]$of such intercellular fluid is not known with any certainty (GREISEMER, 1959). The fluid is, however, said to originate from plasma sources in the looped capillaries and superficial capillary nets of the corium (KUNO, 1956); as the fluid moves upward to the intercellular spaces of the horny layer its $\left[\mathrm{K}^{+}\right]$is probably augmented by the addition of sweat residues and keratinization products (RoTHMAN, 1954) and the $\left[\mathrm{K}^{+}\right]$of that palmar film which is collected at the surface of the horny layer is, from Table 1, of the order of $18.17 \mathrm{mEq} / \mathrm{l}$. We would suggest, then, that the $\left[\mathrm{K}^{+}\right]_{\text {internal }}$ of Eq. (1) might be of this order, given similar temporal and climatic conditions, and that this value provides guidance for the selection of a suitable $\left[\mathrm{K}^{+}\right]_{\text {external. }}$. This figure of 18.17 $\mathrm{mEq} / 1 \mathrm{~K}^{+}$should be considered in relation to Fig. 1, which summarizes group data obtained from 16 male subjects, and shows the reduction in BSPL negativity that can be obtained by manipulating the value of $\left[\mathrm{K}^{+}\right]_{\text {external }}$ below the upper limit of $67 \mathrm{mEq} / 1$. From Eq. (1), the condition when $\left[\mathrm{K}^{+}\right]_{\text {external }}=\left[\mathrm{K}^{+}\right]_{\text {internal }}$ is that of zero potential. Examination of Fig. 1 indicates that recorded BSPL would be zero when $\left[\mathrm{K}^{+}\right]_{\text {external }}$ is of the order of $16 \mathrm{mEq} / \mathrm{l}$, which agrees favorably with the estimate for $\left[\mathrm{K}^{+}\right]_{\text {internal }}$ derived from palmar surface film analyses.

As $67 \mathrm{mEq} / 1$ has been considered to be somewhat high for $\left[\mathrm{K}^{+}\right]_{\text {external }}$ in BSPL recording, a more suitable concentration was selected by taking a value approximately midway between 16 and $67 \mathrm{mEq} / 1$. Therefore, $40 \mathrm{mEq} / 1$ was adopted as a suitable $\left[\mathrm{K}^{+}\right]_{\text {external }}$ for use in the present study.

2. $\left[\mathrm{Na}^{+}\right]_{\text {external }}$. Selection of a physiologically comparable value for $\left[\mathrm{Na}^{+}\right]_{\text {external }}$ requires a similar matching with the value of $\left[\mathrm{Na}^{+}\right]_{\text {internal }}$. It was possible to estimate this from the $\mathrm{Na} / \mathrm{K}$ of palmar surface film, shown in Table 1 . The mean value for $\mathrm{Na} / \mathrm{K}$ being of the order of $2: 1$, the value for $\left[\mathrm{Na}^{+}\right]_{\text {external }}$ would have to be some $2 \times\left[\mathrm{K}^{+}\right]_{\text {external }}$, i.e., $2 \times 40=80 \mathrm{mEq} / \mathrm{l}$.

External electrolytes of $40 \mathrm{mEq} / 1 \mathrm{~K}^{+}$and $80 \mathrm{mEq} / 1 \mathrm{Na}^{+}$were therefore prepared in $2 \%$ agar (VENABLES and SAYER, 1963) and used for the electrophysiological recording as described below.

\section{b) Electrophysiological technique}

The experimental conditions and setting for this study were identical with those previously described (CHRISTIE and VenABLES, 1971a); recordings were made during mornings and afternoons in cool summer weather.

Data were obtained from 40 Caucasian subjects aged between 20 and 40 years; 20 were male and 20 female, all being staff or students of academic institutions.

Skin potential methodology was that advocated by VenABLES and SAYER (1963) using their $\mathrm{Ag} / \mathrm{AgCl}$ system, with electrode placements at palmar and at 
drilled forearm sites; one departure from their recommendations was, as already stated, the use of 40 and $80 \mathrm{mEq} / 1$ concentrations for external $\mathrm{K}^{+}$and $\mathrm{Na}^{+}$ respectively.

Two simultaneous recordings were made from each subject, using identical concentrations of $\mathrm{KCl}$ for one pair of forearm/palmar electrodes, and identical concentrations of $\mathrm{NaCl}$ for the other; for 20 subjects $\mathrm{KCl}$ was used on the dominant and $\mathrm{NaCl}$ on the nondominant limb, the sides being reversed for the remaining 20 subjects.

Palmar electrodes were taped on to midphalangeal forefinger sites (CHRISTIE, 1970) after hands had been washed with hard soap and thoroughly rinsed with water.

BSPL values were obtained during 20 min bed-rest (Christie and VenABLes, 1971a), using two Grass Pl amplifiers; sensitivities were $5 \mathrm{mV} / \mathrm{cm}$ in early parts of the record and $1 \mathrm{mV} / \mathrm{cm}$ when recording "basal" data.

\section{RESULTS}

The value of BSPLs in both the $\mathrm{K}^{+}$and the $\mathrm{Na}^{+}$channels was noted; group data are summarized in Table 2. The significance of differences due to the factors of external electrolyte and sex were tested by an analysis of variance, results of which are summarized in Table 3.

Table 2. Summary of BSPL values $(\mathrm{mV})$ obtained from male and female subjects with $40 \mathrm{mEq} / 1 \mathrm{~K}^{+}$and $80 \mathrm{mEq} / 1 \mathrm{Na}^{+}$as external electrolyte concentrations

\begin{tabular}{cccc}
\hline & $\begin{array}{c}\text { External } \\
\text { electrolyte }\end{array}$ & Mean & Range \\
\hline $\begin{array}{c}\text { Male subjects } \\
(n=20)\end{array}$ & $\begin{array}{c}\mathrm{K}^{+} \\
(40 \mathrm{mEq} / \mathrm{l})\end{array}$ & -11.04 & +6.31 to -29.8 \\
$\begin{array}{c}\mathrm{Na}^{+} \\
(80 \mathrm{mEq} / \mathrm{l})\end{array}$ & -20.98 & -6.15 to -33.2 \\
$\begin{array}{c}\mathrm{K}^{+} \\
(n=20)\end{array}$ & -2.83 & +28.45 to -21.0 \\
& $(40 \mathrm{mEq} / \mathrm{l})$ & -13.58 & +12.45 to -26.2 \\
\hline
\end{tabular}

Examining the differences between BSPL values that can be attributed to differences in the external electrolyte $(F=78.076, P<0.001)$, and inspecting first the ranges presented in Table 2, it is seen that both $\mathrm{Na}^{+}$and $\mathrm{K}^{+}$data have positive potentials at their lower ends. Positive potentials (recorded with external $\mathrm{KCl}$ ) are seen in Fig. 1 as being, in effect, an extension of the decrease in the negativity of BSPL due, in the case of the data summarized in Fig. 1, to the lowering of $\left[\mathrm{K}^{+}\right]_{\text {external }}$ values. Such positive potentials would, according to Eq. (1), be present if $\left[\mathrm{K}^{+}\right]_{\text {internal }}$ were smaller than $\left[\mathrm{K}^{+}\right]_{\text {external, }}$ and one would predict 
Table 3. Analysis of variance data from Table 2 material.

\begin{tabular}{lrrrr}
\multicolumn{1}{c}{ Source } & df & SS & MS & \multicolumn{1}{c}{ F } \\
\hline Between subjects & 39 & 8946.9 & & \\
Sex & 1 & 1312.5 & 1312.5 & $6.533^{*}$ \\
Error variance & 38 & 7634.4 & 200.9 & \\
Within subjects & 40 & 3373.1 & & \\
Electrolyte & 1 & 2262.3 & 2262.3 & $78.076^{* *}$ \\
Electrolyte $\times$ sex & 1 & 9.8 & 9.8 & \\
Error variance & 38 & 1101.1 & & \\
\hline
\end{tabular}

$\mathrm{TSQ} / \mathrm{N}=140874.8 ; n=80 ; \mathrm{SST}=12320.0$

* $P<0.05 ; \quad * * P<0.001$

their appearance if there were indications of high values for $\mathrm{ECF}\left[\mathrm{K}^{+}\right]$. This prediction was supported by the finding of positive BSPL values (recorded with $0.5 \%$ $\mathrm{KCl}$ ) in subjects having particularly high-amplitude T-waves (CHRISTIE and VeNABLES, 1971c). Such T-waves would be associated with high concentrations of plasma $\mathrm{K}^{+}$(PAPADIMITRIou et al., 1970) and therefore, we would argue, with high concentrations of $\mathrm{K}^{+}$in the horny layer's intercellular fluid. Further, we would argue that such intercellular fluid represents the "[ $\left.\mathrm{K}^{+}\right]$internal" of Eq. (1) and that, in consequence, low (i.e., positive) BSPL values are associated with high-amplitude $\mathrm{T}$-waves.

As the $\mathrm{Na}^{+}$data in Table 2 also show positive potentials, it is not unreasonable to suggest that such low BSPL values may be reflecting high concentrations of $\mathrm{Na}^{+}$in epidermal intercellular fluid, and that these represent the " $\left[\mathrm{Na}^{+}\right]_{\text {internal" }}$ of Eq. 1 if it is applicable also to $\mathrm{Na}^{+}$. If the Nernst model is applicable to $\mathrm{Na}^{+}$this implies that the value of BSPL recorded with external $\mathrm{NaCl}$ (BSPL $(\mathrm{NaCl})$ ) is a function of the concentration gradient between the external electrolyte and internal epidermal sources. As a first step in the testing of this suggestion it is important to exclude the possibility that the significant increase in BSPL values associated with the use of $\mathrm{NaCl}$ as the external electrolyte was due solely to its cationic concentration* of 80 in contrast to the $40 \mathrm{mEq} / 1$ of the $\mathrm{KCl}$. That is, it is important to demonstrate that the nature of the external cation (and, therefore, the particular external/internal concentration gradients associated with it) is of significance. If the nature of the cation were irrelevant, then, we would argue, estimates of the internal cation made from the recorded BSPL values of Table 2 and used in Eq. (2) would be similar, regardless of whether they were calculated from $\mathrm{KCl}$ or from $\mathrm{NaCl}$ data, i.e.:

$$
[\text { Cation }]_{\text {internal }} \text { would }=\frac{40 \mathrm{mEq} / 1 \mathrm{~K}^{+}}{\operatorname{antilog}_{10} \frac{\mathrm{BSPL}(\mathrm{KCl})}{61}}=\frac{80 \mathrm{mEq} / 1 \mathrm{Na}^{+}}{\operatorname{antilog} \frac{\mathrm{BSPL}(\mathrm{NaCl})}{61}}
$$

\footnotetext{
* strictly speaking, "activity."
} 
Table 4. Calculation from BSPL $(\mathrm{NaCl})$ and $\mathrm{BSPL} /(\mathrm{KCl})$ of internal cation concentrations ([Cation] internal).

\begin{tabular}{lcc}
\hline \multicolumn{1}{c}{ Source } & BSPL mean $(\mathrm{mV})$ & [Cation] $]_{\text {internal }}(\mathrm{mEq} / \mathrm{l})$ \\
\hline Male, external $\mathrm{NaCl}$ & -20.98 & 36.6 \\
Male, external $\mathrm{KCl}$ & -11.04 & 26.4 \\
Female, external $\mathrm{NaCl}$ & -13.58 & 47.8 \\
Female, external $\mathrm{KCl}$ & -2.83 & 35.9 \\
\hline
\end{tabular}

Using the mean values shown in Table 2, and computing [Cation] $]_{\text {internal }}$ from Eq. (2) results in the set of data presented in Table 4.

Examination of Table 4 shows that values for [Cation] internal computed from BSPL $(\mathrm{NaCl})$ data by means of Eq. (2) are not identical with those computed from BSPL (KCl) data. We conclude, therefore, that the nature of the external cation (and its associated external/internal concentration gradients) remains of significance, and that the increase in BSPL $(\mathrm{NaCl})$ values cannot be attributed to its cationic concentration being greater than the $40 \mathrm{mEq} / 1$ of $\mathrm{K}^{+}$.

From the assumption that computations using Eq. (1) are appropriate for $\mathrm{Na}^{+}$ data, it becomes possible to derive calculated values for the $\mathrm{Na} / \mathrm{K}_{\text {internal }}$ ratios, which, from Table 4, are 1.375 and 1.335 for male and female groups respectively. These values approach the empirical data for palmar surface film Na/K (1.96 and 1.76) which were obtained in cool weather at midday during earlier studies. As some of the BSPL data from which the calculated $\mathrm{Na} / \mathrm{K}$ values are derived were obtained in the afternoon this could account for their being lower than the empirical values derived from palmar surface film collected at noon; there is a diurnal variation in BSPL values recorded with $0.5 \% \mathrm{KCl}$ (ChrISTIE, 1970) and a nadir in the afternoon. From Eq. (1) such a nadir would be associated with the highest $\left[\mathrm{K}^{+}\right]_{\text {internal }}$, and therefore with the lowest $\mathrm{Na} / \mathrm{K}_{\text {internal }}$; as the palmar surface $\mathrm{Na} / \mathrm{K}$ values were obtained from samples collected at noon, it could be expected that the intercellular fluid from which the surface film originated would have higher $\mathrm{Na} / \mathrm{K}$ values than would exist during afternoon hours.

Turning now to the significant differences in BSPL values $(F=6.533, P<$ 0.05 ) associated with the factor of sex, we do not have previous BSPL or palmar surface data from female subjects, against which this result can be adequately viewed; as, therefore, our interpretation must be to some extent speculative, it is incorporated into the Discussion section that concludes this report.

\section{DISCUSSION}

This study had as its primary aim a comparison of the properties of $\mathrm{NaCl}$ and $\mathrm{KCl}$ as external electrolytes for recording BSPL. The comparison was undertaken with what were estimated to be physiologically similar concentrations 
of $\mathrm{Na}^{+}$and $\mathrm{K}^{+}$, which approached the values obtaining in horny layer intercellular fluid.

The BSPL data recorded with $\mathrm{NaCl}$ could be used in computations based on the Nernst equation and compared with previously obtained data from analyses of palmar surface film. The results of these computations and comparisons suggest that $\mathrm{NaCl}$ has properties similar to those of $\mathrm{KCl}$ when used, in the conditions stated, as an external electrolyte for BSPL recording.

This in turn suggests that the Nernst model is appropriate for $\mathrm{Na}^{+}$in the way that it appears to be for $\mathrm{K}^{+}$, in which case the inability of NIIMI et al. (1968) to demonstrate a concentration effect must be attributed to some factor other than the use of $\mathrm{Na}^{+}$.

It is possible that, if the Nernst model is appropriate to the concentration effect, the range of concentrations selected by NIIMI et al. was inappropriate; a suitable range could be calculated from the range of BSPL $(\mathrm{NaCl})$ values obtained in the present study. It should be emphasized, however, that such a concentration range ought, ideally, to be used in climatic and temporal conditions similar to those of the present study: there is a diurnal variation in BSPL (recorded with $\mathrm{KCl}$ ) which suggests a diurnal variation in $\left[\mathrm{K}^{+}\right]_{\text {internal, }}$ and there are seasonal and climatic effects on body fluid electrolytes (Collins and WEINER, 1968). Evidence for the latter statement is seen in the differences in palmar surface $\left[\mathrm{K}^{+}\right]$seen in Table 1.

It is possible that a climatic effect, not on body fluid electrolytes, but on palmar eccrine sweat glands could preclude the demonstration by NIIMI et al. (1968) of a concentration effect; if ambient temperatures were high enough to induce thermoregulatory sweating in palmar eccrine glands, the complexity of the resulting electrodermal situation (Fowles and VeNABLES, 1970) could mask a concentration effect in the way suggested in relation to arousal sweating of nonhabituated subjects.

Turning to the significant differences in BSPL values attributable to the sex factor (Table 3), in the absence of palmar surface film analyses for female subjects it is possible only to speculate on the origin of significant differences. Thus the calculated values for female $\left[\mathrm{K}^{+}\right]_{\text {internal }}$ and $\left[\mathrm{Na}^{+}\right]_{\text {internal }}$ seen in Table 4 may represent sex differences in the intercellular concentrations of these ions, but it is also possible that some additional nonsudorific factor, which may be hormonal, is affecting female skin potential levels. Until more is known about the precise mechanism by which "basal" potentials are generated, however, we are able only to speculate.

What would seem to be essential now is more detailed knowledge of the way in which the $\mathrm{Ag} / \mathrm{AgCl}$ electrodes, physiologically appropriate external electrolyte, and the abraded and intact epidermal tissue interact to generate "basal" palmar skin potential levels. 
In conclusion, we would argue that such investigation of the nature of the biophysical mechanisms underlying the generation of BSPL has value beyond the borders of psychophysiology. Yoshimura (1964) has described the role of the skin as a mobile reservoir of water and electrolytes which defends the intravascular compartment; it seems possible that BSPL phenomena such as it s diurnal variation and its reduced negativity during sleep following a stressful day (CHRISTIE, 1970) reflect this adaptive function of the skin. If this can be shown to be the case, then BSPL methodology may be able to provide a simple and sensitive method for monitoring electrolyte shifts within the human organism.

\section{REFERENCES}

Christie, M. J. (1970) Temporal aspects of palmar skin potential, and related cardiovascular and electrolyte measures. Ph.D. diss. University of London.

Christie, M.J. and Venables, P. H. (1971a) Characteristics of palmar skin potential and conductance in relaxed human subjects. Psychophysiology, 8, 523-532.

Christie, M. J. and Venables, P. H. (1971b) Effects on "basal" skin potential level of varying the concentration of an external electrolyte. J. Psychosom. Res., 15: 343-348.

Christie, M. J. and Venables, P. H. (1971c) Basal palmar skin potential and the electrocardiogram T-wave. Psychophysiology, 8, in press.

Collins, K. J. and WeIner, J. S. (1968) Endocrinological aspects of exposure to high environmental temperatures. Physiol. Revs., 48: 785-839.

EDELBERG, R. (1963) Electrophysiological characteristics and interpretation of skin potentials. USAF School of Aerospace Medicine Tec. Doc. Rep., 63-95.

Fowles, D. C. and Venables, P. H. (1970) The effects of epidermal hydration and sodium reabsorption on palmar skin potential level. Psychol. Bull., 73: 363-378.

Greisemer, R. D. (1959) Protection against the transfer of matter through the skin. In The Human Integument, ed. by Rothman, S. A.A.A.S., Washington.

Kuno, Y. (1956) Human Perspiration. Charles C. Thomas, Springfield, Illinois.

Leiderman, P. H. and Shapiro, D. (1964) Studies on the galvanic skin potential level: Some behavioural correlates. J. Psychosom. Res., 7: 277-281.

Martin, I. and Venables, P. H. (1966) Mechanisms of palmar skin resistance and skin potential. Psychol. Bull., 65: 347-357.

Mashima, S., Fu, L. and Fukushima, K. (1965) The effect of oral potassium chloride on the normal and abnormal electrocardiogram. Jap. Heart J., 6: 463-473.

Neumann, E. (1968) Thermal changes in palmar skin resistance patterns. Psychophysiology, 5: 103-111.

Nimi, Y., Yamazaki, K. and Watanabe, T. (1968) Pseudo-effects of external electrolyte concentration on measured skin potential levels. Psychophysiology, 5: 188-191.

PAPAdimitriou, M., Roy, R. R. and VARKARAKIS, M. (1970) Electrocardiographic changes and plasma potassium levels in patients on regular haemodialysis. Brit. Med. J., 2: 268.

Rothman, S. (1954) Physiology and Biochemistry of the Skin. University of Chicago Press, Chicago.

Venables, P. H. and Martin, I., eds. (1967a) A Manual of Psychophysiological Methods. North-Holland Publishing Co., Amsterdam.

VenABles, P. H. and MARTIN, I. (1967b) The relation of palmar sweat gland activity to level of skin potential and conductance. Psychophysiology, 3: 302-311.

Venables, P. H. and SAYer, E. (1963) On the measurement of the level of skin potential. Brit. J. Psychol., 54: 251-260.

Yoshimura, H. (1964). Organ systems in adaptation: The skin. In A.P.S. Handbook of Physiology, ed. by DiLB, D. B. Sec. 4, Williams \& Wilkins, Baltimore. 